\title{
Pulling back the curtains: the realities and complexities of juggling parenthood and a career in academia
}

\author{
Kerry F. Crawford and Leah C. Windsor, The PhD Parenthood Trap: Caught \\ Between Work and Family in Academia, Georgetown University Press, \\ 2021
}

\section{Shannon Mason ${ }^{1}$ D}

Accepted: 26 January 2022 / Published online: 3 March 2022

(c) The Author(s), under exclusive licence to Springer Nature B.V. 2022

In September 2020, environmental engineer and academic Dr. Gretchen Goldman posted two photos on the social media platform Twitter. In the first photo, Dr. Goldman is seen being interviewed on a television news program. The neatly-appointed living room decor in the background tells us that she is being interviewed from home, and the words flashing on the chyrons remind us of what needs no reminding: we are in the midst of a global pandemic. In the second photo, we see the out-of-camera shot: Dr. Goldman dressed in shorts, the floor strewn with children's toys, and a laptop placed on a chair placed precariously on a coffee table. The Tweet went viral, as they say, making the rounds on social media, and even making its way to mainstream media channels (Ritschel, 2020). The image caught the public attention because it provided a rare tiny glimpse behind the scenes of juggling parenthood and a career.

In their book, The PhD Parenthood Trap: Caught Between Work and Family in Academia, Dr. Kerry Crawford and Dr. Leah Windsor show that such complicated messiness is a common reality for many working in academia. Their book provides more than just a glimpse into this rarely seen and seldom discussed world; it pulls the curtains wide open to reveal intimate and detailed insights into various aspects that impact the careers, health, and well-being of academic parents. The book was finalized in the early stages of the COVID-19 pandemic, and so, while the stories and study findings that are presented throughout the book do not capture this "new reality," the challenges that are facing academic parents have not really changed. They have, however, been compounded and exacerbated (Lantsoght et al., 2021), making the book all the more timely and necessary.

Like much of the literature that is positioned at the nexus of parenthood and academia, the impetus of the book comes from the personal experiences of the authors, and thus, it is a book written by academic parents, about academic parents, and for (but not only for) academic parents. The book is about parenthood in its various forms, and while it gives some attention to the experience of fathers, it has a clear focus on mothers. This is well justified as multiple studies in various contexts have shown that working mothers continue to

Shannon Mason

shan@nagasaki-u.ac.jp

1 Faculty of Education, Nagasaki University, Nagasaki, Japan 
assume a larger share of child care and household duties (e.g., Bianchi et al., 2000; Canelas \& Salazar, 2014), and at the same time are subject to the well-acknowledged "motherhood penalty" (Morgan et al., 2021). Formal support for academic parents is often lacking within higher education institutions (HEIs), and thus, books such as this are highly valuable to those who are in the midst of struggle, providing a source of commiseration, guidance, solidarity, and ultimately, hope.

In each chapter, the authors cleverly blend two sources of data that are commonly found in the (albeit limited) extant literature, but which are rarely combined: survey data and autoethnographic accounts. The book is guided in content and structure by the findings of an original survey study. Approximately 300 academic parents responded to the anonymous, online survey, making it a relatively large-scale study on this topic. The survey itself, which is included as an appendix, is composed of just over one hundred items, gathering data using short-answer, multiple choice, Likert scale items, and open-ended questions, allowing the collection of a range of different data on a variety of topics. These topics provide the focus for each of the chapters, which thread descriptive statistics, prominent themes identified in the responses, as well as direct quotes from participants. Also threaded through the chapters are autoethnographic reflections from more than 20 contributors. In this way, the book builds on several other notable titles that have collated personal essays from academic parents (e.g., DeRoche \& Berger, 2017; Evans \& Grant, 2008). These vignettes provide first-hand accounts that bring richness and rawness to each topic.

The topics covered are wide-ranging. The early chapters give attention to the experience of academic parents through the career trajectory from doctoral researcher (Chapter 2), through early career and navigating the tenure track (Chapter 3 ), to the daily challenges of an academic career (Chapter 4). Chapter 4 is entitled "The Elusive Work-Life Balance" and the chapter, and much of the book, looks to dismantle common advice given to parents, and particularly mothers, that they can "have it all" and that a "work-life balance" is possible, if only they would just "lean in" — but remember to "wait until tenure to have children." The social expectations of what it takes to be a "good" parent, and the institutional expectations of what it takes to be a "good" academic (CohenMiller \& Demers, 2019) collide in such a way that many academic parents do indeed find themselves "caught between work and family." Because the authors are academic parents themselves, and because the book centers the experiences of academic parents, no time is wasted with such platitudes and instead focuses on actionable advice and realistic recommendations (as discussed later).

The latter chapters in particular make important new contributions to the current discourse. Attention is given to issues that are somewhat taboo within the walls of academia and thus rarely discussed openly, such as the physical impact of parenthood (Chapter 6), the adoption process, issues of fertility, miscarriage and child loss (Chapter 7), and breastfeeding and lactation (Chapter 8). Chapter 7 is a particularly emotional read as women share their stories of grief after miscarriage, chemical pregnancy, or loss of a child. In some cases, support from colleagues and administrators is forthcoming, and in others, there is ambivalence or even hostility. For the most part, however, women stay silent about their experiences. That some of the contributors chose to remain anonymous is testament to the fact that these issues remain a taboo in the academy (and outside it); further support that sharing these stories is necessary, for both reader and storyteller.

In Chapter 5, but also scattered throughout the book, we hear directly from those who are not often centered in the literature, such as academic parents of color, fathers and nonbirth parents, single parents, adoptive parents, and same-sex couples. We hear from Dr. Whitney Pirtle, who as a Black and first-generation doctoral researcher had to contend not only with issues of gender during her doctoral journey but also of class and race. The book 
touches on these and other social inequalities and includes a diversity of voices, but as it aims to capture a broad range of experiences, it does not go into great depth into the distinct and compounded issues faced by academic parents with intersecting identities. Further reading of more focused studies is recommended to complement the broad focus of this book, such as those that are specifically focused on the intersection of sexism and racism in academia (e.g., Bourabain, 2021; Hinton-Johnson, 2011; Nzinga-Johnson, 2013; Rogers et al., 2019).

The book is clearly focused on the USA, although as an academic parent who has worked in two disparate non-US contexts, I found all of the stories and discussions interesting if not highly relatable, and many of the issues raised are perhaps much more "universal" than the book at times implies. Survey responses from non-US participants are used to highlight the "striking" contrast between the USA and "other countries," so much so that "many problems ... appear to be unique to academics in the United States" (p. 20), even considered "non-issues." However, it would be a rare country that has adequate and equitably accessible programs and policies to support all academic parents. Even in countries like Australia and New Zealand that have universal health care and generous parental leave schemes, academic parents have reported struggling with limited institutional support (Hardy et al., 2018; Harris et al., 2019). I found myself at times searching for a more detailed description of the participant sample, but unfortunately, the national contexts of the non-US respondents, who appear to make up almost one fifth of the sample, is not provided. The book may have had expanded its applicability had it engaged in a more explicit and nuanced way with the international participants, but in any case, the book would certainly be of interest to readers from a range of higher education contexts.

Perhaps the most important contribution of the book is its inclusion of lists of explicit recommendations, in the form of best practices, found at the end of each chapter, and in the final Chapter 9, Looking Back, Moving Forward. The experiences of academic parents are centered in the book, and so, some of the recommendations provide advice and support directly to academic parents themselves. Informed by the experiences of the authors, and the contributions from the survey participants and vignette contributors, advice includes (but is far from limited to) getting informed about institutional policies, developing a core network of supporters within the academy, and keeping detailed written records. However, the onus is not placed on academic parents to make HEIs more inclusive and supportive of academic parents, and the majority of the recommendations are directed explicitly to those in positions of authority: administrators, department chairs, and unit heads. These recommendations could also apply to those in direct support roles, such as principal investigators and doctoral supervisors. The authors' goal is "nothing short of institutional reform," and there is ample attention given to the systematic processes and practices within academia (and broader society) that continue to place academic parents, and particularly mothers, in a position of disadvantage. It is only through subverting these broader societal mechanisms that real change can ever take place.

In summary, The PhD Parenthood Trap: Caught Between Work and Family in Academia, is a valuable source of guidance for current academic parents, parents who are considering an academic career, or academics looking to grow their family. It is equally important as a resource for those in positions of authority in higher education, and is an essential text for developing a broad yet intimate view of the realities of parenting in the academy, and highlighting the ways and extent to which parents are impacted and disadvantaged. This book provides a vital space for academic parents to safely voice their concerns, so they no longer have to hide behind a curtain of silence and taboos. It is incumbent on those in positions of power in HEIs to listen to those voices, and to heed the informed 
recommendations offered, and to act to promote the diversity, inclusion, and equity as they so often espouse.

\section{References}

Bianchi, S. M., Milkie, M. A., Sayer, L. C., \& Robinson, J. P. (2000). Is anyone doing the housework? Trends in the gender division of household labor. Social Forces, 79(1), 191-228. https://doi.org/10. $1093 / \mathrm{sf} / 79.1 .191$

Bourabain, D. (2021). Everyday sexism and racism in the ivory tower: The experiences of early career researchers on the intersection of gender and ethnicity in the academic workplace. Gender Work Organization, 28(1), 248-267. https://doi.org/10.1111/gwao.12549

Canelas, C., \& Salazar, S. (2014). Gender and ethnic inequalities in LAC countries. IZA Journal of Labor \& Development, 3, A18. https://doi.org/10.1186/2193-9020-3-18

CohenMiller, A., \& Demers, D. (2019). Conflicting roles of mother and academic? Exploring the use of arts-based self-care activities to encourage wellbeing. Art/Research International: A Transdisciplinary Journal, 4(2), 611-645. https://doi.org/10.18432/ari29391

DeRoche, C., \& Berger, E.D. (2017). The parent track: Timing, balance, and choice in academia. Wilfrid Laurier University Press.

Evans, E., \& Grant, C. (2008). Mama, PhD: Women write about motherhood and academic life. Rutgers University Press.

Hardy, A., McDonald, J., Guijt, R., Leane, E., Martin, A., James, A., Jones, M., Corban, M., \& Green, B. (2018). Academic parenting: Work-family conflict and strategies across child age, disciplines and career level. Studies in Higher Education, 43(4), 625-643. https://doi.org/10.1080/03075079.2016. 1185777

Harris, C., Myers, B., \& Ravenswood, K. (2019). Academic careers and parenting: Identity, performance and surveillance. Studies in Higher Education, 44(4), 708-718. https://doi.org/10.1080/03075079. 2017.1396584

Hinton-Johnson, K. (2011). Choosing my best thing: Black motherhood and academia. In T. R. Berry \& N. Mizelle (Eds.), From oppression to grace: Women of color and their dilemmas within the academy (pp. 155-167). Stylus. https://digitalcommons.odu.edu/teachinglearning_fac_pubs/86/. Accessed 5 Feb 2022.

Lantsoght, E., Tse Crepaldi, Y., Tavares, S. G., Leemans, K., \& Paig-Tran, E. (2021). Challenges and opportunities for academic parents during COVID-19. Frontiers in Psychology, 12, 645734. https://doi.org/ 10.3389/fpsyg.2021.645734

Morgan, A.C., Way, S.F., Hoefer, M.J.D., Larremore, D.B., Galesic, M., \& Clauset, A. (2021). The unequal impact of parenthood in academia. Science Advances, 7(9): eabd1996. https://doi.org/10.1126/sciadv. abd1996

Nzinga-Johnson, S. (Ed.) (2013). Laboring positions: Black women, mothering and the academy. Demeter Press.

Ritschel, C. (2020). Environmental engineer's photo reveals the reality of parents working from home amid ongoing pandemic. Independent. https://www.independent.co.uk/life-style/work-from-homeparent-environmental-engineer-center-for-science-and-democracy-gretchen-goldman-b454394.html. Accessed 5 Feb 2022.

Rogers, J., McLean, A., \& Mentor, M. (2019). A seat at the table: Womanist narratives of Black mothers in doctoral programs. Taboo: The Journal of Culture and Education, 18(1), 87-108. https://doi.org/10. 31390/taboo.18.1.07

Publisher's note Springer Nature remains neutral with regard to jurisdictional claims in published maps and institutional affiliations. 